\title{
APRENDENDO A DESAPRENDER: A (DES) CONSTRUÇÃO DO DISCURSO DE GÊNERO COM JOVENS DO ENSINO MÉDIO
}

LEARNING TO UNLEARN:

THE DESCONSTRUCTION OF GENDER DISCOURSE WITH YOUNG PEOPLE FROM A PUBLIC HIGH SCHOOL

\section{Antonia Milena Elmiro Furtado Cid', Luiza Eridan Elmiro Martins de Sousa², Eden Batista Duarte ${ }^{3}$}

RECEBIDO EM: 31/03/2020 | ACEITO EM: 15/06/2020

DOI: $10.5902 / 2317175843255$

\section{RESUMO}

O presente trabalho analisa os discursos de jovens do ensino médio de uma escola pública situada no município de Forquilha, Ceará, Brasil, identificando as relações de gênero e como estas se configuram no ambiente escolar. Para tanto, apresenta uma discussão teórica sobre juventude, diversidade e sexualidade. Utilizou-se a abordagem qualitativa e os dados foram coletados por meio da observação participante e de quatro grupos focais formados a partir de 33 alunos. Os resultados demonstram a necessidade de um diálogo frequente sobre gênero e sexualidade no ambiente escolar, visto que os próprios jovens manifestaram interesse em discutir sobre os conflitos que permeiam a vida juvenil ou, mais especificamente, as questões afetivas, sexuais e de diversidade de gênero. Sobre o jovem, principalmente no ensino médio, recaem inúmeras cobranças em relação aos estudos, trabalho, relacionamentos, e de posicionamento diante de determinados fatos, inclusive acerca de sua sexualidade.

Palavras-chave: Gênero; Juventude; Escola.

\footnotetext{
1 Graduada em Ciências Sociais pela Universidade Estadual Vale do Acaraú; Especialista em Gestão, Coordenação, Avaliação e Planejamento Escolar pelo Instituto Superior de Teologia Aplicada - Faculdades INTA; Mestranda em Sociologia pela Universidade Federal do Ceará.

2 Graduação em Psicologia pela Universidade Federal do Ceará; Especialista em Psicologia Social; Mestra em Políticas Públicas e Sociedade pela Universidade Estadual do Ceará; Doutoranda em Psicologia pela Universidade Federal do Ceará.

3 Mestre e Doutor em Engenharia pela Universidade Federal do Ceará.
} 
APRENDENDO A DESAPRENDER: A (DES) CONSTRUÇÃO DO DISCURSO DE GÊNERO

COM JOVENS DO ENSINO MÉDIO

\section{ABSTRACT}

The present study analyzes the speeches of high school youths of a public school located in the city of Forquilha, Ceará, Brazil, in order to identify the gender relations and how these are configured in the school environment. Therefore, it presents a theoretical discussion about youth, diversity and sexuality. A qualitative approach was used and data were collected through participant observation and four focus groups formed from 33 students. The study demonstrates the need for frequent dialogue about gender and sexuality in the school environment. Young people have shown interest in discussing the conflicts surrounding youth life such as affective, sexual and gender diversity issues. Many demands are made on young people in high school, in relation to studies, work, relationships, and even their sexuality.

Keywords: Gender; Youth; School.

\section{Introdução}

Pesquisar sobre gênero é um grande desafio. A forma como são construídos os conceitos do que significa ser homem e ser mulher, e as relações que daí derivam, estruturam nossa sociedade e, nesse sentido, atingem todos (as) os (as) indivíduos (as), inclusive pesquisadores e pesquisadoras. Cada autor (a), a partir de suas leituras e contextos, supõe ou (re) afirma determinado conceito sobre gênero, estabelecendo uma relação entre corpo, gênero e sexualidade, contribuindo para o entendimento do que o corpo e a sexualidade representam perante o gênero, afetando ou não o seu significado para determinadas sociedades.

Assim, discutir gênero é tarefa árdua de desconstrução e nesta empreitada não se pode negar a forte influência dos "campos teóricos e políticos" (LOURO, 2006, p. 211) que interferem no modo de captação do que ele representa. Neste contexto, destaca-se o movimento feminista, que teve bastante influência no avanço dos estudos de gênero, pois, com a forte militância e ousadia de um movimento social, as integrantes reunidas foram instigadas a pensar e questionar esses papéis considerados masculinos ou femininos, começando a perceber que "gênero é um conceito desenvolvido para contestar a naturalização da diferença sexual em múltiplos terrenos de luta" (HARAWAY, 1995, p. 221).

Considerando a contestação desses processos tidos como naturais, o presente trabalho buscou compreender como as representações de papéis sociais, a partir de uma perspectiva das relações de gênero, são identificadas pelos (as) jovens de uma escola pública estadual situada no município de Forquilha, na região norte do estado do Ceará, Brasil. O estudo se justifica pela necessidade de que questionamentos sejam levantados sobre gênero no espaço educacional, levando em consideração que a juventude é considerada uma fase de mudanças e um período de cobranças e imposições de escolhas por 
representar determinados papéis perante a sociedade. Os (as) jovens que fazem parte do ensino médio também sentem as distinções claramente impostas no seu cotidiano escolar, seja no mercado de trabalho ou nas relações afetivas e sexuais. Buscou-se, assim, compreender como os (as) alunos (as) vivenciam e identificam essas relações na escola e em seu cotidiano.

\section{Referencial teórico}

\section{1 (Des) construindo os conceitos de gênero}

É possível perceber em diversas esferas sociais a desigualdade existente entre homens e mulheres, tornando, a partir dessa dinâmica das relações, compreensível que haja uma naturalização dos processos. Em outras palavras, as relações de poder são assimiladas como naturais; como a norma da sociedade. Butler demonstra que "o gênero é culturalmente construído; consequentemente, não é nem o resultado casual do sexo nem tampouco tão aparentemente fixo quanto o sexo" (BUTLER, 2018, p. 25). Nessa perspectiva, constata-se a imensidão que o conceito de gênero carrega e as distinções que resultam das diversas culturas existentes.

Segundo Dornelles e Meyer (2013), o conceito de gênero demonstra a pluralidade e conflitos dos processos pelos quais a cultura define e distingue os corpos entre sujeitos masculinos e femininos, e a questão de gênero se relaciona e se intersecciona com outros marcadores sociais, como classe, raça, etnia, produzindo "modificações importantes nas formas pelas quais feminilidades e masculinidades, no plural, são (ou podem ser), vividas e experienciadas" (p. 50).

Embora essa pluralidade seja evidente, ainda há um processo de negação dessas modificações que se sobressai diante das desnaturalizações de gênero e sexo. O sexo biológico é normalmente vinculado ao gênero, contudo as ciências sociais procuram desconstruir esse conceito, pois "a identidade social é, portanto, socialmente construída" (SAFFIOTI, 1987, p. 10). Ou seja, não é o sexo biológico que vai definir se o indivíduo pertence ao gênero feminino ou masculino e nem irá impor a sua sexualidade. Diante disso, Dornelles e Meyer enfatizam que,

Corpo, aqui, não é entendido como um ente biológico, mas como algo que se constrói no cruzamento entre o que aprendemos a definir como natureza (ou biologia) e como cultura ou, dito de outro modo, na interseção entre aquilo que herdamos geneticamente e aquilo que aprendemos quando nos tornamos sujeitos de uma determinada cultura (DORNELLES; MEYER, 2013, p. 47-48).

A sociedade constrói culturalmente o que representa um homem e uma mulher, impondo papéis sociais, tendo em vista que "a sociedade delimita, com bastante precisão, os campos em que pode operar a mulher, da mesma 
forma como escolhe os terrenos em que pode atuar o homem" (SAFFIOTI, 1987, p. 8). Essa realidade é notória em nossa sociedade, exatamente pela delimitação desses campos de atuação e das normas de comportamentos. Como exemplos, dificilmente se vê uma mulher atuando no campo da engenharia, física, informática, ou um homem sendo professor de dança. É impossível negar essas conexões imediatas quando se fala de algo que já faz referência ao ser homem ou ao ser mulher.

Para Scott (1995), o antagonismo que é produzido entre homens e muIheres afeta o processo de subjetividade do sujeito enquanto ser social, pertencente a determinada sociedade e com funções e papéis sociais a cumprir. Da mesma forma que algumas atitudes são naturalmente impostas à mulher, o homem também passa por essa norma, seja na criação da submissão feminina ou no processo de demanda de poder ao homem, de tal modo que "mesmo ficando em aberto a maneira como o 'sujeito' é construído, a teoria tende a universalizar as categorias e a relação entre o masculino e o feminino" (SCOTT, 1995, p. 16).

Ressaltamos que o corpo foi por um longo tempo o determinante do gênero, tendo em vista que aos olhos da nossa sociedade os órgãos sexuais eram responsáveis por definir se o indivíduo fazia parte do gênero feminino ou masculino, sem levar em consideração a sua identidade, bem como o reconhecimento desta. Como consequência dessa delimitação, tornou-se comum ouvir que "o homem é o chefe da casa" e "a mulher é a esposa do lar". Essas, entre tantas outras falas, ainda são ouvidas em pleno século XXI. Isto é, ainda há uma ligação entre corpo e gênero, apesar dos diversos processos de desnaturalização dessa conexão existente.

Existem distinções sobre o que o homem ou a mulher devem fazer diante de determinadas situações, como em uma festa, no restaurante, no lar, na escola etc. São ditadas normas, haja vista que esse aspecto faz parte de uma construção histórica e cultural, gerando processos concebidos como naturais para uma classificação e delimitação do que vem a fazer parte do mundo masculino e do feminino, pressupondo que "cada sociedade elabora distintos significados para o mesmo fenômeno natural" (SAFFIOTI, 1987, p. 9).

Desse modo, é possível citar a forma como crianças são educadas em nossa sociedade, na qual, desde a adolescência, o menino é estimulado a trabalhar para ser o provedor do lar. Por consequência, será ele quem "mandará" na casa. Já a menina é estimulada a aprender a arrumar a casa, lavar louça e/ ou roupa, além de cuidar de bebês, ou seja, é moldada a ser dona de casa e cuidar, seja dos filhos ou do futuro esposo. Quando essas normas são rompidas, ocorre um choque e é isso que vem acontecendo nos dias atuais, pois os padrões estão sendo desconstruídos. À vista disso, mulheres e homens têm ganhado espaço em lugares que antes eram padronizados segundo o gênero.

Heilborn (1994) tenta esclarecer o que vem a ser gênero, estabelecendo uma teoria sobre o sentido de gênero, desconstruindo a classificação comum 
que atribuímos ao ser homem e ao ser mulher, uma vez que "as propriedades simbólicas particulares à constituição do masculino e do feminino são fenômenos da relação hierárquica entre eles" (HEILBORN, 1994, p. 2). Nessa perspectiva, Villela e Arilha argumentam,

Enquanto seres sexuados, percebemo-nos e situamo-nos no mundo como mulheres ou como homens. Tal percepção, embora tome como base a anatomia corporal visível, é mais prescritiva do que descritiva, pois o que é captado da corporeidade não é apenas "tenho uma vagina" ou "tenho um pênis", e sim, "devo ser, sentir e me comportar deste ou daquele modo". O gênero constitui o modo como nos relacionamos com nós próprios e com o outro. Assim, incide no processo de produção simbólica, definindo a maneira como cada um percebe o mundo, apreende os códigos de interpretação da cultura e estabelece pautas de interação com o outro, marcando a atuação social de cada indivíduo (VILLELA; ARILHA, 2003, p. 115).

Bourdieu (2011), em seu livro "A Dominação Masculina", discorre sobre o poder que se impõe nas significações e que mascara as relações, considerando que não reconhecemos determinados hábitos e estruturas como sendo referentes ao poder de um sujeito sobre outro. Consequentemente, na divisão existente entre os sexos, nem sempre há uma percepção de que determinadas atitudes são referentes ao dominante, e que o dominado está sendo dominado.

O citado autor faz referência ao que é comum considerar como ordem social nas relações de gênero. Afinal, foi construída uma naturalização das atitudes e processos sociais e, quando algo foge do padrão desta "ordem das coisas", é comum que haja alguma forma de discriminação, pois habitualmente interiorizamos essas ações como imutáveis. Sendo assim, é necessário identificar como esses processos acontecem e de que forma são assimilados pelos indivíduos. Nas sociedades, há sempre o dominado e o dominante, todavia a mulher normalmente ocupa o papel de dominada, seja física ou simbolicamente. Diante da naturalização dessas ações, os indivíduos acabam por contribuir, às vezes involuntariamente, para que esses acontecimentos se tornem constantes.

Para este estudo é importante considerar a desigualdade existente entre homens e mulheres e questionar sobre a causa dessa disparidade entre os sexos, visto que é impossível negar o binarismo existente em que a mulher é considerada o oposto do homem. Para "rejeitar o caráter fixo e permanente da oposição binária, precisamos de uma historicização e de uma desconstrução autêntica dos termos da diferença sexual" (SCOTT, 1995, p. 18). Entretanto, para tal fim, é primordial inicialmente entender como a diferença sexual e de gênero implicam no cotidiano dos indivíduos, fomentando relações de poder.

Diante dessa perspectiva, é importante observar a construção social da 
qual os indivíduos fazem parte como fator relevante para suas atitudes e hábitos, pois a construção do sujeito enquanto ser social acontece no seu meio, de acordo com suas vivências e regras (ou normas) sugeridas por fortes instituições da nossa sociedade, como a família e a escola. Além disso, essas relações são marcadas por várias interseções como etnia, classe social e geração. Portanto, é importante analisar como ocorrem as distinções dos papéis sociais a partir de uma perspectiva de gênero e juventude.

\section{$2.2 \mathrm{~A}(\mathrm{~s})$ juventude(s) e o contexto escolar}

A juventude, assim como o gênero, é uma construção histórica e social, uma vez que os conceitos referentes a esses termos variam de acordo com cada sociedade. No Brasil, segundo as políticas públicas de juventude, pode ser considerado (a) jovem quem tem entre 15 e 29 anos. Novaes (2007) argumenta que "na sociedade moderna, embora haja variação dos limites de idade, a juventude é compreendida como um tempo de construção de identidades e de definição de projetos de futuro" (2007, p. 1). Segundo Dayrell:

Construir uma noção de juventude na perspectiva da diversidade implica, em primeiro lugar, considerá-la não mais presa a critérios rígidos, mas como parte de um processo de crescimento mais totalizante, que ganha contornos específicos no conjunto das experiências vivenciadas pelos indivíduos no seu contexto social (DAYRELL, 2003, p. 42).

Mais uma vez, é significativo enfatizar a relevância do contexto social, histórico e cultural em que o sujeito vive, pois isso o impulsiona a pensar e reproduzir alguns hábitos, costumes e crenças. De acordo com o ponto de vista que os indivíduos detêm de determinadas situações e sujeitos, "jovens são o que são, mas também são (sem que o sejam) o que deles se pensa, os mitos que sobre eles se criam. Esses mitos não refletem a realidade embora a ajudem a criar" (PAIS, 2008, p. 242).

Sendo assim, fala-se em juventudes, no plural, abrangendo as mais variadas especificidades do (a) jovem de acordo com seus desejos e crenças culturais, sem esquecer que "o debate sobre juventude, no Brasil, principalmente a partir das décadas de 80 e 90, trouxe o olhar da diversidade" (CASTRO, 2009, p. 186).

Os (as) jovens que estão inseridos nas séries do ensino médio pertencem a uma diversidade cultural e têm como base seu contexto histórico e social, impulsionando assim a sua forma de pensar e agir diante de determinadas situações e construindo os desejos a partir dessas perspectivas. O (a) jovem vai à escola em busca de algo, seja de conhecimento, amizades, brincadeiras, ou até mesmo de utilizar essa instituição como uma ponte para algo que almeja no futuro (faculdade, trabalho, entre outros) e, a partir desse impulso inicial, são criadas novas redes ou novos grupos, de tal forma que a escola passa a ter significado e sentido para os (as) discentes. 
É crucial compreender que a escola está imersa em um contexto carregado de significados, acumulando diversas realidades - meio rural, meio urbano, classe média, classe baixa, entre outras - que fazem parte de determinados grupos - ideológicos, religiosos, culturais -, e isso implica um emaranhado de descobertas e um processo de reaprendizagem e adaptação constante, pois os (as) jovens que ali estão têm sede de algo. A escola se torna, pois, responsável por contemplar essas expectativas e suprir algumas das necessidades que eles (as) carregam.

Sobre a escola, Dornelles e Meyer (2013) reforçam o caráter complexo e plural desse ambiente no qual convivem, de forma nem sempre harmoniosa, diferentes grupos e sujeitos sociais. Deste modo, as relações de gênero estão presentes em todos os ambientes e não podem deixar de serem discutidas na escola, que é considerada por alguns (mas) estudantes como a segunda casa, por representar um espaço de encontro e acolhida, mas também de contrastes e conflitos. Além disso, "ao falarmos de juventudes é necessário refletir sobre a escola, por ser esta um lugar de socialização, de construção de identidade e busca por formação para a vida e para o mercado de trabalho" (SILVA, 2010, p. 32).

Nesse contexto de construção, a escola pode vir a reproduzir imagens negativas e preconceituosas dos indivíduos. Tal aspecto precisa ser averiguado e analisado para que seja possível uma compreensão acerca do que esse espaço representa e possibilita, de acordo com suas especificidades e seu papel institucional. Vale ressaltar que a escola tem grande valor e representatividade para o (a) jovem. Muitas vezes faz parte de um status pertencer ou não a determinada instituição, levando em consideração que, "ao serem indagados, nas pesquisas, sobre as 'instituições sociais' em que mais confiam, os jovens citam sempre a escola [...] vista como um bom lugar para se fazer amigos e integrante da sociabilidade que caracteriza a condição juvenil (NOVAES, 2007, p. 107).

Os processos que vêm se construindo e desabrochando no ambiente escolar precisam ser observados, já que estão diretamente ligados à personalidade dos (as) discentes. Sendo assim, influenciam no modo de ver a sociedade e suas características. Nesse universo, a vida social do indivíduo também está cercada de fatores relacionados ao gênero. Infelizmente, percebe-se que ainda existem inúmeras formas de preconceitos no ambiente escolar, além de atitudes que são consideradas, por muitos (as) discentes e funcionários (as), como brincadeiras, contudo são ofensas verbais e/ou físicas aos homossexuais. Ao que tudo indica, além de o homossexual e a mulher serem inferiorizados, eles (as) também recebem 'chacotas'.

A instituição escolar, por tradição, ao classificar sujeitos pela classe social, etnia e sexo, tem historicamente contribuído para (re) produzir e hierarquizar as diferenças. Assim, coloca à margem aqueles que não estão em conformidade com a norma hegemônica e, certamente, não contempla a inclusão da diversidade sexual proposta na atualidade (ALBUQUERQUE, 2012, p. 15). 
Essa repressão pode acontecer de diversas maneiras, seja através das falas, dos olhares ou das normas de comportamento impostas pela escola. Por isso, não se pode deixar de falar nas diferenças de gênero e o que isso ocasiona dentro dos espaços escolares. As identidades estão sendo construídas e reformuladas a partir de cada nova experiência, e a escola tem como tarefa transferir e construir conhecimentos junto ao corpo discente, tornando possível que este possa identificar os diversos aspectos da realidade, além de reconhecer e respeitar o espaço individual que possui sua própria subjetividade e modo de vida.

Portanto, a fim de melhor compreender as relações atuais de gênero entre as juventudes de uma escola de ensino médio, buscou-se analisar o que significa ser homem e ser mulher no ambiente escolar e quais funções e características são impostas de acordo com o gênero ao qual pertencem.

\section{Método de pesquisa}

Adotou-se o método qualitativo para a realização da pesquisa. Heilborn (2003) aponta que é através deste método que se consegue estranhar, desnaturalizar e conhecer os mecanismos sociais cotidianos. Geertz (1997) também alerta sobre o estranhamento que precisa ser efetivado diante de determinada realidade, levando em consideração o fato de que não é possível fazer pesquisa se existir uma naturalização do objeto pesquisado.

Para a coleta de dados utilizaram-se a observação participante e grupo focal (GF). O trabalho de observação foi indispensável, tendo em vista que os dados foram coletados observando-se as atitudes dos (as) discentes no ambiente escolar. Nessa abordagem, "o pesquisador-observador se torna parte integrante de uma estrutura social e, na relação face a face com os sujeitos da pesquisa, realiza a coleta de informações, dados e evidências" (MARTINS; THEÓPHILO, 2009, p. 87). A observação participante foi realizada pela pesquisadora Cid de forma semanal durante o horário das aulas de sociologia e nos intervalos, participando, sempre que possível, de diálogos e debates que envolviam os estudos de gênero, visando aproximar-se do campo de pesquisa de maneira sistemática e coletar dados que pudessem subsidiar a análise, bem como o roteiro para realização dos GF. Na ocasião, a pesquisadora tinha a oportunidade de dialogar com os (as) interlocutores e conhecer aspectos da dinâmica escolar e das percepções dos (as) jovens discentes.

Além da observação participante, optou-se por trabalhar com GF para a coleta de dados, "sua escolha encontra-se condicionada à orientação teórico-metodológica da investigação, do objeto de investigação e da real necessidade de dados e informações a serem coletados" (NETO, MOREIRA; SUCENA, 2002 , p. 3). Uma das principais finalidades da utilização da técnica de GF é reunir informações detalhadas sobre algum tema, proposto por um (a) pesquisador (a) que pode estar atuando como coordenador (a) ou moderador (a) do grupo, dessa forma, 
O GF é definido como uma técnica de pesquisa na qual o Pesquisador reúne, num mesmo local e durante um certo período, uma determinada quantidade de pessoas que fazem parte do público-alvo de suas investigações, tendo como objetivo coletar, a partir do diálogo e do debate entre eles, informações acerca de um tema específico (NETO, MOREIRA; SUCENA, 2002, p. 5).

Foram realizados quatro GF, tendo sido dois grupos com meninas e dois com meninos, abrangendo discentes de todas as séries do ensino médio, durante o segundo semestre de 2012. Optou-se por realizar o grupo focal separadamente com meninos e meninas, com o objetivo de ampliar a compreensão sobre as representações dos papéis sociais identificados por eles e elas no ambiente escolar e em seu cotidiano. Ao selecionar os (as) participantes, buscou-se inserir perfis diversos, que variaram desde o local de moradia até as séries, entre outros aspectos, a fim de atingir o objetivo da pesquisa. Participaram 16 meninas e 17 meninos, somando um total de 33 estudantes. O roteiro norteador de perguntas dos grupos focais foi formado por questões sobre sexualidade, juventude, família, escola, gênero e diversidade, com a finalidade de estimular os (as) discentes a discutirem sobre os temas.

$\mathrm{Na}$ articulação para execução dos grupos focais, contou-se com o apoio de uma interlocutora que era responsável pela disciplina de sociologia. As atividades dos GF eram iniciadas no período do intervalo e estendiam-se para além desse horário. Cada sessão durava em torno de 90 minutos e empregava-se um aparelho gravador para registro dos diálogos. Vale ressaltar que a autora Sousa atuou como observadora, ao passo que a autora Cid desenvolveu o papel de coordenadora dos grupos focais, contribuindo para a mediação a partir do roteiro norteador.

\section{Apresentação e discussão dos resultados: análise dos discursos}

\subsection{Questões de gênero e juventude}

Inseridos na proposta da pesquisa apresentada, dois termos ganham destaque: gênero e juventude. O primeiro tem sido cada vez mais objeto de pesquisa nas ciências sociais e se constitui hoje como uma importante área de estudo. O segundo apresenta uma conceituação ampla e que varia de acordo com a sociedade - cada povo possui uma espécie de ritual que categoriza quem faz parte da juventude -, assumindo grande significância.

A juventude da escola que fez parte do estudo considera que a principal característica dessa fase da vida é a liberdade. Por outro lado, não julga fácil ser jovem, em função da responsabilidade e pressão impostas pela família, conforme destacado abaixo: 
APRENDENDO A DESAPRENDER: A (DES) CONSTRUÇÃO DO DISCURSO DE GÊNERO COM JOVENS DO ENSINO MÉDIO

\begin{abstract}
O difícil eu acho que é o mais óbvio: tá sendo cobrado de você a responsabilidade. Justamente por ser um jovem, tem a cobrança em cima de você. Como se eles quisessem que a gente fosse lapidado, como se fosse apenas um tijolo na parede; que esse é o lado ruim. Tem muita pressão em cima, de você ter muita responsabilidade, você leve tudo a sério. O lado bom é que esse lado ruim nos ajuda. O lado ruim faz com que a gente amadureça; que a gente realmente tenha responsabilidade com algo que é imposto (Aluno do $3^{\circ}$ ano do Ensino Médio).
\end{abstract}

Meninas consideram que a juventude é embutida de responsabilidades, de decisões e principalmente de cobranças. Aliás, além de responsabilidade, o que os (as) demais participantes dos GF destacaram com maior ênfase foi a cobrança - por parte da família, principalmente - de atitudes que acarretem um futuro promissor e que zelem pela sua "moral".

É perceptível que ambos os sexos passam por essa transição no processo juvenil, todavia os papéis sociais são reproduzidos de forma que os meninos são mais cobrados pela família em relação ao trabalho, enquanto as meninas são estimuladas a desenvolverem competências para realizar os afazeres domésticos, ou estudar, para assim conseguirem empregos considerados mais "leves".

De um modo geral, os (as) jovens reconhecem essas divisões como algo "natural". Entretanto, algumas meninas expressam seu desejo de ingressar na universidade e conquistar uma profissão a partir dos estudos, ao passo que outras, da zona urbana, ressaltam a vontade de se tornarem independentes "para não dependerem de homens". Por esse ângulo, compreende-se que alguns comportamentos e atitudes operam rupturas com o modelo dominante, contudo, em contrapartida, as meninas que desejam ser independentes financeiramente também relatam seu desejo pelo casamento e pela maternidade. Esse anseio faz parte de todos (as) os (as) jovens participantes do GF. Independentemente do sexo, eles (as) salientaram a vontade de "construir uma família". Quando questionados se há diferença entre ser jovem mulher e ser jovem homem, grande parte acredita que sim, como citaram os (as) discentes:

\footnotetext{
Eu acho que o pai não se preocupa tanto com o menino como se preocupa com a menina. O menino desde pequeno já vai soltando e a menina fica em casa cuidando das coisas. Pra homem não importa a idade, mulher é presa todo tempo dentro de casa (Aluna do $2^{\circ}$ ano).

Os pais dão mais liberdade para os homens, pois eles acham que os homens já têm o pensamento maduro e as mulheres não (Aluno do $3^{\circ}$ ano).
}

A família apresenta-se, enquanto instituição, responsável pela socialização primária dos (as) jovens e, uma vez marcada pela hierarquização do gênero, contribui para a perpetuação da subordinação feminina. Nos casos supracitados, a garota considera que a mulher normalmente "é mais presa 
pelos pais", pois eles alegam que estão "zelando" pela filha. O rapaz reafirma esse fato, enfatizando a liberdade que é concedida ao homem.

Já no caso a seguir, temos um jovem que discorda desse pensamento e acredita que não há diferença entre ser jovem mulher e ser jovem homem.

Particularmente eu não acho diferente, alguns podem achar. Na nossa idade a gente pode ver a diferença, mas ser jovem homem e ser jovem mulher, eu acho que não há diferença, porque eu acho que ambos querem realmente ser um jovem de ação, mudar alguma coisa. Jovem masculino a gente já pensa que ele é aquele mais machão, quer fazer tudo, quer fazer melhor, já a mulher, os homens pensam que a mulher é aquela mais sensível, mas isso é totalmente equivocado, porque a gente tá vendo elas chegarem a lugares que a gente não imaginava. Homens e mulheres fazendo muitas mudanças, principalmente na política, jovens políticos. Eu acho que não há diferença ser jovem mulher e ser jovem homem. (Aluno do $2^{\circ}$ ano do Ensino Médio).

Observam-se dois tipos de pensamento que refletem a realidade dos (as) discentes da escola, sendo indispensável admitir que "as relações entre homens e mulheres certamente vêm se transformando (...), mas as interpretações para as mudanças estão longe de ser convergentes" (LOURO, 2012, p. 93).

As mulheres não se libertaram totalmente, acredito que nesse ponto de vista os pais ainda hoje veem as mulheres como sexo frágil. A mulher não pode isso, a mulher não pode aquilo, já o homem pode, e essas distinções estão bem presentes no nosso convívio. (Aluna do $2^{\circ}$ ano).

Destaca-se essa distinção de papéis sociais em que o homem tem mais espaço e liberdade e a mulher vai sendo ensinada desde a infância a arrumar a casa para que possa se tornar uma "boa esposa" aos olhos da sociedade. Às mulheres é ainda destinado o espaço privado, reconhecendo, dessa forma, que o homem continua ocupando o espaço público como algo natural e exclusivo dele.

\subsection{Questões de gênero e o espaço escolar}

O espaço escolar, como qualquer outro espaço social, é organizado por regras e normas, sejam elas simbólicas ou concretas. Os grupos que se formam dentro deste meio constroem e ressignificam alguns espaços, dando a eles características próprias. Dessa maneira, é comum que os (as) estudantes recém-chegados (as) permaneçam em lugares que não são ocupados por grupos que fazem parte daquele contexto, pois estão conhecendo o ambiente e vendo quais espaços é possível frequentar. 
APRENDENDO A DESAPRENDER: A (DES) CONSTRUÇÃO DO DISCURSO DE GÊNERO COM JOVENS DO ENSINO MÉDIO

\begin{abstract}
$\mathrm{Na}$ instituição escolar, estão presentes as concepções de gênero e sexuais que, histórica e socialmente, constituem uma determinada sociedade (...). Em outras palavras, a escola (em seu espaço físico, em seus regulamentos, currículos, normas, programas, em suas práticas, nas falas, atitudes e gestos das pessoas que ali convivem) é atravessada pelas concepções de masculinidade e feminilidade, pelas formas de sexualidade de uma dada sociedade (LOURO, 2012, p. 94).
\end{abstract}

$\mathrm{Na}$ escola avaliada existem diversos espaços para os grupos se reunirem. Na hora do intervalo, os meninos costumam ocupar a quadra de esportes para se encontrar e conversar. As meninas que também frequentam a quadra normalmente são namoradas, paqueras ou amigas bem próximas deles, pois há uma delimitação simbólica dos espaços. Em geral, elas costumam ficar nos corredores, no pátio da escola ou atrás das salas, reunidas em grupos. Os corredores são ocupados por discentes de ambos os sexos, porém dificilmente um grupo incorpora ao mesmo tempo meninas e meninos.

\title{
4.3 Questões de gênero e o trabalho
}

Há distinções entre homens e mulheres em diversos "campos" e no trabalho não seria diferente. Apesar das mudanças que vêm ocorrendo no último século, permitindo à mulher ganhar mais espaço no mercado de trabalho, ainda é possível perceber que as tarefas domésticas normalmente são destinadas a elas, e a fala de uma aluna participante do GF confirma esse fato: "lá em casa é só eu e minha mãe, o resto é tudo homem, e a responsabilidade cai tudo pra cima de mim e dela, fazer as coisas, as tarefas".

A sociedade investe muito na naturalização deste processo. Isto é, tenta fazer crer que a atribuição do espaço doméstico à mulher decorre de sua capacidade de ser mãe. De acordo com este pensamento, é natural que a mulher se dedique aos afazeres domésticos, aí compreendida a socialização dos filhos, como é natural sua capacidade de conceber e dar à luz (SAFFIOTI, 1987, p. 09).

Saffioti (1987) destaca essa naturalização da atividade doméstica que, mesmo com o crescimento da mulher no mercado de trabalho, ainda "estabelece" que ela é a responsável pelas tarefas domésticas e não as demais pessoas que fazem parte do seu convívio diário: pai, filho, esposo, irmão etc. Presume-se que a divisão sexual do trabalho ainda é muito presente em nossa sociedade, havendo uma delimitação de funções. Quando a mulher ou o homem realiza funções que antes não eram concebidas a eles (as), ocorre discriminação ou preconceito, pois o que antes estava naturalizado, agora está passando por um processo de desconstrução. 
No Brasil (...) houve modificação na divisão do trabalho doméstico nos grandes centros urbanos, devido à inserção crescente das mulheres no mercado de trabalho e à sua grande participação em atividades profissionais fora do domicílio. No entanto, essa mudança tem um caráter tópico e não atinge o âmbito das responsabilidades domésticas, que continuam a ser atribuídas, pela sociedade, exclusivamente às mulheres (HIRATA, 2003, p. 115).

Esse fato faz parte da realidade dos (as) jovens. Um dos alunos, ao ser questionado sobre as tarefas domésticas, declarou que considera que "a muIher gosta mais de fazer as coisas do que o homem. Tipo assim, ela tem mais vontade de trabalhar, cuidar da casa, e nem todos os homens têm." As meninas que participaram dos GF demonstraram insatisfação sobre esse fato, declarando que, por haver certa sobrecarga sobre as mulheres, gostariam que as tarefas pudessem ser divididas, independentemente do sexo. Apenas uma delas, moradora da zona rural, ressaltou que gosta de limpar e arrumar a casa, "toda vez que eu arrumo casa eu fico me entretendo".

Nesta lógica, os (as) jovens deixam transparecer que os pais cobram mais dos meninos em relação ao trabalho, "pois eles (pais) impõem que a mulher é pra tá da cama pro fogão e do fogão pra cama, e homem tem que trabalhar pra sustentar a família. A partir dos 18 anos se o homem não trabalhar, é vagabundo. A sociedade impõe isso".

Outra garota entrevistada pondera que alguma mudança tem ocorrido, mas a concepção original ainda persiste: "Hoje em dia é cobrado dos dois, né? Mas geralmente é do homem. Quando têm dois filhos, uma menina e um menino, eles vão logo aprendendo que o homem é que tem que sustentar a casa e a menina tem que cuidar da casa".

Apesar da considerável publicidade feita para mudar os "papéis sexuais", os homens ainda controlam os status de alta renda, de alto poder e de alto prestígio; e eles ainda são capazes de ser evasivos a muito trabalho doméstico, mesmo quando suas esposas trabalham fora. Como isso é possível? A resposta reside na socialização dos homens e das mulheres dentro de crenças sobre feminilidade e masculinidade, e em práticas discriminatórias nos mercados de trabalho. Estas são causas sutis, mas seus efeitos são profundos (TURNER, 2000, p, 131).

Quando questionados (as) sobre profissões masculinas e femininas, as meninas enfatizaram o já citado crescimento da mulher no mercado de trabalho, alcançando profissões que antes eram destinadas exclusivamente ao homem. Por sua vez, os meninos ainda acreditam que as mulheres não realizarão algumas tarefas masculinas, por serem consideradas "pesadas". Constantemente, é possível identificar discursos dessa natureza em que se procura ressaltar que "a mulher é sexo frágil" ou que "não é capaz de fazer parte de uma profissão que exerça força física". 
A sociedade está se modificando e os (as) jovens participantes dos GF já demonstram o desejo por mudanças que é transmitido através de seus discursos e anseios por variadas profissões, não apenas as consideradas femininas e/ ou masculinas, mas todo o enorme campo de possibilidades diante do mercado de trabalho e ascensão social. Vale ressaltar que os meninos que participaram dos GF pensam em exercer profissões bem remuneradas para que seja possível sustentar o lar e a família. Apesar de a mulher poder ter uma profissão, muitos homens continuam sentindo a necessidade de permanecerem sendo provedores do lar, tanto no aspecto econômico, quando na tomada de decisões.

\subsection{Questão de gênero e as relações afetivo-sexuais}

Através dos discursos, ficou evidente que, nos dias atuais, é comum ouvir falar em namoro, "fica" e "rolo", entre tantos outros termos que configuram as relações afetivas e sexuais. Esses termos não são utilizados apenas por meninos. As garotas também aderem a essas novas formas de se relacionar e de nomear tais relações.
A cultura delimita alguns percursos identitários para diferentes grupos. E o jovem, gregário por definição, encontra e constrói novos papéis por meio da socialização com seus pares, exercen- do, pela sexualidade, uma forma preponderante de sociabili- dade e de construção da identidade (ABRAMOWAY; CASTRO; SILVA, 2004, p. 69).

Mesmo diante de tantas possibilidades de se relacionar, há em cada categorização diversas singularidades que são responsáveis por diferenciá-las. Uma pergunta que gerou bastante inquietação nos participantes dos GF foi sobre a rotulação de indivíduos:

Tem muita menina que fica com todo rapaz, tá atrás, assim, não se dá o valor, acha que porque é mulher fica com quem quer, e não é obrigada a ser reservada, nem a dar satisfação a ninguém. A gente vê muito, eu tenho até umas amigas assim, que corre atrás de homem. (Aluno do $3^{\circ}$ Ano).

Nesse contexto, é fundamental perceber como a sexualidade feminina é regulada pela sociedade. Na visão desses jovens, existem moças que são consideradas sérias, estudiosas e que não "ficam" com vários garotos sem assumir compromisso sério com nenhum deles. Estas são as "pessoas para namorar". Já aquelas que gostam de sair constantemente, que ficam ou beijam várias pessoas, são apenas para ficar. Segundo Foucault, "entende-se por moral como um conjunto de valores e regras de conduta que são propostos aos indivíduos e aos grupos por meio de diversos aparelhos prescritivos, como podem ser a família, as instituições educativas, as Igrejas etc." (2004, p. 211). Assim, com- 
preende-se que estes jovens rapazes estão arraigados de preconceitos construídos pela sociedade, sendo levados a realizar cobranças sobre determinadas condutas para que algumas meninas possam se tornar suas namoradas.

Esse "processo de seleção" normalmente parte dos meninos. Para as meninas, os discursos sugerem uma forma de pensar diferenciada: "se eu ficar com um cara e ele for uma pessoa do mundo, eu posso mudar a concepção dele, posso mudar a cabeça dele. Aí, vai que ele se transforma em uma pessoa que é pra namorar" (Aluna do $2^{\circ}$ Ano).

A sexualidade cada vez mais ganha espaços em estudos e pesquisas. Há uma compreensão da necessidade de se debater sobre as diferentes formas de se relacionar e os desejos afetivos e sexuais, sendo também importante frisar sobre as transformações que vêm ocorrendo na sociedade. Todavia, há ainda um modelo heteronormativo que impõe algumas atitudes que são consideradas "normais" perante a sociedade, e quem não se encaixa nesses padrões é visto como diferente ou "anormal".

Aparentemente supõe-se que todos os sujeitos tenham uma inclinação inata para eleger como objeto de seu desejo, como parceiro de seus afetos e de seus jogos sexuais alguém do sexo oposto. Consequentemente, as outras formas de sexualidade são construídas como antinaturais, peculiares e anormais (LOURO, 2010, p. 17).

A escola é certamente um espaço de vivências diferenciadas do meio habitual, e os (as) discentes a consideram "uma ponte para um futuro melhor". Todavia, esse ambiente não é apenas um espaço de oportunidades, escolhas e afetos. Vários sentimentos, realidades e angústias fazem parte desta instituição que muitos chamam de "segunda casa", considerada como "um espaço essencial de socialização" (BRANDÃO; MIRANDA, 2012, p. 105). Há diversos modelos de relações, alguns pautados nos vínculos afetivos, outros moldados por preconceitos. É possível identificar essas duas perspectivas tanto na escola como em outras instituições, porém este espaço é um ambiente de construção, formação e, em alguns casos, é um grande influenciador de discriminação.

Nesse sentido, "a escola, que deveria ser libertadora, vai nutrir a violência e levar ao sofrimento" (BRANDÃO; MIRANDA, 2012, p. 5). Logo, esses processos precisam ser reavaliados, pois a instituição, enquanto formadora de opiniões, deve pensar as práticas que estão sendo incentivadas e, muitas vezes, prejudicando indivíduos. Em 2013, um aluno, homossexual, foi agredido dentro da escola pelos seus colegas de turma. Ele participou do GF e relatou o fato:

Aluno': Tem o caso do nosso colega aqui, acho que virou coisa comum no colégio, homossexuais por ter uma opção sexual diferente ser agredido tanto fisicamente quando verbalmente, moralmente. Aqui realmente houve casos em que a agressão física ocorreu e, às vezes, eu não concordo, porque a escola en- 
APRENDENDO A DESAPRENDER: A (DES) CONSTRUÇÃO DO DISCURSO DE GÊNERO COM JOVENS DO ENSINO MÉDIO

cobre isso, porque isso era pra ser um aviso pra você depois 'vim' abordar esse assunto, essa questão da opção sexual, só porque não é hétero, não quer dizer que você não é normal. Eu acho que isso deveria ser um aviso pra esse tema ser abordado, o preconceito, mas não acontece. Eles encobrem isso, porque a escola não quer ser vista como um mau exemplo; tem que ser a escola perfeita, em que não ocorre nenhum caso desse tipo. $E$ nós, que estamos inseridos aqui, sabemos da realidade.

Pesquisador: Pode relatar como foi?

Aluno3: Foi assim: bateu o sinal pra gente sair, minha sala 'tava' no laboratório de matemática e todo mundo saiu correndo pra pegar as coisas. Eu peguei as minhas coisas, entrei na sala, peguei as coisas e tinha umas coisas mais lindas do mundo na porta, empurrando Deus e o mundo, não deixando sair. Deixaram as meninas bonitas passarem e os amigos, quando eu fui passar, pedi licença, todo educado, sem falar que essas pessoas são do meu carro, e eu até falei assim "gente vocês não vão logo não? O carro já tá saindo". Eles me empurraram, e eu disse pra não me empurrarem. Como diz o povo, o sangue sobe e ferve, então o que foi que eu fiz. Eu me atrevi a dar um murro. Aí o que fizeram, me empurraram pra cima da mesa, e vieram dizendo "anda, vamos bater nele", e uma amiga minha, a Aluna", disse pra eles não me baterem, e o outro insistiu dizendo pra me baterem, e a Aluna' dizendo pra eles não me baterem. Eles se atreveram a me dar um murro e acertou no braço da Aluna?. Ficou roxo. Aí a Aluna ${ }^{1}$ mandou eu ir embora, e eu tive que ir pra não perder o carro. Eu sou tão idiota, que me chamo de idiota porque quando eu cheguei no carro ele 'tava' lá, e o que foi que eu fiz? Nada, sentei no chão e chorei.

Pesquisadora: E a escola fez o quê?

Alguns: Nada.

Aluno': Encobre, isso é o que revolta.

Aluno2: Não dá punição aos alunos.

Essa é uma realidade muitas vezes comum em diversas escolas, públicas ou privadas. É por este motivo que "precisamos voltar nosso olhar para a instituição escolar e para os processos pedagógicos" (MEYER; SOARES, 2012, p. 43) e investigar como a escola vem atuando diante de situações de violência verbais ou físicas. É inegável o preconceito existente nesses espaços contra negros (as), pobres, homossexuais ou até mesmo os que são direcionados às adolescentes que estão grávidas.

O corpo e suas ressignificações são os motivos principais para "zuações" e brincadeiras consideradas de "mau gosto". Os alunos ressaltam que "não adianta ele se sentir bem se têm outras pessoas que fazem ele se sentir mal. Se ele vai ao banheiro têm os gaiatos que ficam tirando sarro dele" (Aluno do $2^{\circ}$ Ano).

O corpo a que nos referimos, além de ser produzido e ressignificado no centro de variadas redes de poder e controle, é, também, percebido e vivido de forma conflituosa e ambígua, de tal forma que esses modos de viver o corpo envolvem ao mesmo 
tempo, disciplinamento, coerção, subordinação, saúde, libertação, gozo e prazer (MEYER; SOARES, 2013, p. 44).

O aluno homossexual que foi agredido se reconhece como mulher, usa maquiagem e brinco, porém ainda frequenta o banheiro masculino. Apesar das "brincadeiras" constantes dos colegas, ele relatou que as amigas da escola o ajudam a enfrentar esses obstáculos, sempre o defendem e até já sugeriram um nome social para ele. No entanto, ele não quer ser reconhecido por um nome feminino, admitindo um apelido relacionado ao seu nome no registro de nascimento, de forma que consegue manter um vínculo com sua identidade de nascimento ao mesmo tempo em que a mantém com sua identidade sexual.

A homofobia, quando sentida e aceita, pode ser interiorizada como vergonha de si mesmo, aprisionando, fazendo com que os homossexuais se escondam e se tornem invisíveis para não serem identificados como tal. E quando interiorizam e aceitam essa discriminação e preconceito, por medo, insegurança ou sentimento de inadequação, também estão se submetendo a uma situação de subordinação e violência (BRANDÃO; MIRANDA, 2012, p. 6).

A escola, enquanto instituição social, precisa renovar e restabelecer vínculos com os (as) discentes e docentes, para que os (as) estudantes acreditem que esse é um espaço de mudança no qual podem não somente apreender, como também construir novas histórias e identidades. Infelizmente, na prática, nem sempre é possível considerar a escola como uma instituição de referência no ato de proteger a diversidade e zelar pela formação cidadã dos (as) alunos (as). Às vezes, é um espaço ameaçador.

Durante as observações, alguns alunos heterossexuais costumavam "brincar" com os (as) homossexuais, agarrando-os, pegando nas nádegas, perguntando quando iriam poder ficar e se eles, alunos homossexuais, iriam aceitar. É possível identificar que alguns já se adaptaram a essas "brincadeiras", mas outros se chateiam, ficam indignados por não poderem viver a sua sexualidade tranquilamente, sem se privar ou silenciar, pois há preconceito quando alguém se diferencia dos padrões tidos como naturais, através da sexualidade, do estilo de se vestir ou de se comunicar, entre outras coisas.

De acordo com Sabat (2012), é necessário criar condições para que discussões sobre gênero façam parte do cotidiano escolar, aumentando as possibilidades de educar sujeitos para uma sociedade na qual a diferença seja vista com respeito, não como problema. Logo, frisar sobre a influência dessas discussões é fundamental, por se tratar de uma necessidade que não é exclusiva dos (as) discentes, mas de todos (as) aqueles (as) que compõem e constroem o ambiente escolar. 


\section{Considerações finais}

O estudo apontou para a premente necessidade de um diálogo frequente sobre gênero, sexualidade e os demais conflitos que permeiam a juventude no contexto escolar. Observou-se que sobre o (a) jovem pesa uma carga, principalmente no ensino médio, de cobranças, em relação aos estudos, trabalho, relacionamentos e posicionamento diante de determinados fatos.

Identificaram-se disparidades diante dos relacionamentos. Jovens moças não "podem" ficar com vários rapazes, pois passam a ser desvalorizadas e consideradas meninas que "não servem para namorar". Por outro lado, os meninos continuam tendo o direito de se relacionar com quantas meninas desejarem sem ocorrer essa estigmatização. É notável a diferença existente entre os gêneros, como também a naturalização desses processos. No imaginário dos (as) jovens, há ainda resquícios de uma sociedade patriarcal e considerada machista que naturaliza o processo de subordinação da mulher diante do homem.

Também é válido salientar sobre a negação das diversas formas de viver a sexualidade, pois, visivelmente, há discriminação contra homossexuais, e esse fato faz com que alguns (mas) sejam inibidos (as) no ambiente escolar, acarretando exclusão e violência simbólica ou física.

No imaginário das alunas, percebeu-se o desejo de se tornarem independentes financeiramente para, segundo elas, "não depender de homem nem para comprar o absorvente". Nota-se assim a mudança de mentalidade no universo feminino, em que a mulher sai do espaço privado doméstico e adentra o público, ocupando lugares que até bem pouco tempo era designado exclusivamente ao homem, principalmente no mercado de trabalho. Todavia, o fato de trabalhar fora não a liberta dos afazeres domésticos e, dessa forma, ela acaba por vivenciar uma dupla jornada de trabalho.

Curiosamente, apesar do anseio de se tornarem independentes, as muIheres continuam desejando o casamento como parte de um ciclo. A priori, querem estudar, concluir ensino superior e só então casar. Logo, o que se modifica é apenas o fato de optarem por serem autônomas financeiramente, pois continuam tendo a necessidade de possuir um companheiro para que a felicidade seja alcançada. Nesse aspecto, os meninos também apontam seu desejo pelo casamento, ressaltando a vontade que possuem de construir uma família. Todavia, embora compreendam que a mulher está se ressignificando em nossa sociedade, eles permanecem com a pretensão de trabalhar para sustentar a família e continuar sendo o provedor do lar, fortalecendo, ainda que inconscientemente, a "dominação simbólica" (BOURDIEU, 2011).

Por fim, foi significativo o interesse demonstrado pelos jovens para discutir a temática sobre gênero e sexualidade, algo que faz parte de uma realidade tão pessoal. Sob esse aspecto, a escola, sendo formadora de pessoas, deve estimular o senso crítico dos (as) discentes e ampliar sua visão sobre a diversidade existente, estimulando a quebra de preconceitos, o respeito e a valorização das diferenças. 


\section{Referências bibliográficas}

ABRAMOWAY, M.; CASTRO, M. G.; SILVA, L. B. da. Juventude e Sexualidade. Brasília: UNESCO, 2004.

ALBUQUERQUE, R. N. de. Como trabalhar o respeito e a diversidade sexual na escola. In: Construir Notícias. Recife, 2012, ed. 67.

BOURDIEU, P. A dominação masculina. Tradução: Maria Helena Kunher, 10ª ed., Rio de Janeiro: Bertrand Brasil, 2011.

BRANDÃO, S. e MIRANDA, V. dos S. N. Homofobia e Invisibilidade na educação. Seminário Nacional de Educação, Diversidade Sexual e Direitos Humanos, 2012. Disponível em: http://periodicos.ufes.br/gepss/article/ view/3888/3103.

BUTLER, Judith P. Problemas de gênero: feminismo e subversão da identidade. $16^{a}$ ed. Tradução: Renato Aguiar. Rio de Janeiro: Civilização Brasileira, 2018.

CASTRO, E. G. de. Juventude rural no Brasil: processos de exclusão e a construção de um ator político. Revista Latinoamericana de Ciencias Sociales, Niñez y Juventud, Vol. 7, Núm. 1, enero-junio, 2009.

DAYRELL, J. O jovem como sujeito social. Revista Brasileira de Educação. Rio de Janeiro, n²4, Set/Dez, 2003.

DORNELLES, P. G.; MEYER, D. E. Corpo, Gênero e Sexualidade na escola: Cenas contemporâneas, políticas emergentes e teorias potenciais. In: O Recôncavo Baiano sai do armário. Org. Ana Cristina Nascimento Givigi e Priscila Gomes Dornelles. Editora UFRB, 2013.

FOUCAULT, M. Ética, sexualidade e política. Rio de Janeiro: Forense, 2004.

GEERTZ, C. J. Do ponto de vista do nativo. In: O saber local: novos ensaios em antropologia interpretativa. Petrópolis: vozes, 1997.

HARAWAY, Donna. Ciencia, cyborgs y mujeres: La reinvención de la naturaleza. Manuel Talens. Valencia: Madrid: Ediciones Catedra, 1995.

HEILBORN, M. L. De que gênero estamos falando? In: Sexualidade, Gênero e Sociedade, ano 1, n 2 CEPESC/IMS/ UERJ, 1994.

HEILBORN, M. L. Estranha no ninho: sexualidade e trajetória de pesquisa. In: Pesquisas Urbanas: desafios do trabalho antropológico/ Gilberto Velho e Karina Kuschnir (orgs.) - Rio de Janeiro: Jorge Zahar Ed., 2003.

HIRATA, H. e MARUANI, M. (orgs). As novas fronteiras da desigualdade entre homens e mulheres no mercado de trabalho. Senac. 2003

LOURO, G. L. Gênero, sexualidade e educação: das afinidades políticas às tensões teórico-metodológicas. In: GT Gênero, sexualidade e educação na 29a Reunião Anual da Anped, em Caxambu, MG, 2006.

LOURO, G. L. Pedagogias da sexualidade. In: LOURO, G. L. (Org.). O corpo educado: pedagogias da sexualidade. 3. ed. Belo Horizonte: Autêntica, 2010.

LOURO, G. L. Sexualidade: lições da escola. Org. Dagmar Elisabeth Estermann Meyer... [et al.]. In: Saúde, Sexualidade e Gênero na educação de jovens. Porto Alegre: Mediação, 2012.

MARTINS, G.A.; THEÓPHILO, C.R. Metodologia da investigação científica para ciências sociais aplicadas. 2.ed. São Paulo: Atlas, 2009.

MEYER, D. E. E; DORNELLES, P. G. Corpo, gênero e sexualidade na escola: cenas contemporâneas, políticas emergentes e teorias potenciais. In: O recôncavo baiano sai do armário. Bahia, UFRB, 2013.

MEYER, Dagmar E. E.; SOARES, Rosângela de F. R. Corpo, gênero e sexualidade: desafios para a educação escolar. In: Saúde, Sexualidade e Gênero na educação de jovens. Porto Alegre. Editora Mediação, 2012.

MEYER, Dagmar E. E.; SOARES, Rosângela de F. R. Corpo, gênero e sexualidade: desafios para a educação escolar. In: MEYER, Dagmar E. Estermann; SOARES, Rosângela de Fátima R.; DALLA ZEN, Maria Isabel H.; XAVIER, Maria Luisa M. de Freitas (Org.). Saúde, sexualidade e gênero na educação de jovens. Porto Alegre: Mediação, 2012.

NETO, O. C., MOREIRA, M. R. e SUCENA, L. F. M. Grupos focais e pesquisa social qualitativa: o debate orientado como técnica de investigação. XIII Encontro da Associação Brasileira de Estudos Populacionais. 
APRENDENDO A DESAPRENDER: A (DES) CONSTRUÇÃO DO DISCURSO DE GÊNERO COM JOVENS DO ENSINO MÉDIO

Minas Gerais, 2002.

NOVAES, R. Juventude e Sociedade: jogos de espelhos. Sentimentos, percepções e demandas por direitos e políticas públicas. Revista Sociologia Especial - Ciência e Vida. São Paulo, outubro de 2007.

PAIS, J. M. Culturas de Grupo. In Mário Ferreira Lages e Artur Teodoro de Matos (Coordenação), Portugal. Recursos de Interculturalidade. Contextos e dinâmicas, Lisboa, Alto-Comissário para a Imigração e Diálogo Intercultural, 2008.

SABAT, R. F. R. Só as quietinhas vão casar. In: Saúde, Sexualidade e Gênero na educação de jovens (org) Dagmar Elisabeth Meyer... [et al.]. - Porto Alegre: Mediação, 2012.

SAFFIOTI, H. I. B. O poder do macho. São Paulo: Moderna, 1987.

SCOTT, J. W. Gênero: uma categoria útil de análise histórica. Educação \& Realidade. Porto Alegre, vol. 20, n 2,jul./dez. 1995.

SILVA, I. P. da. Escola e relações de gênero: visões de mundo de jovens do ensino médio em Taguatinga. 2010. Dissertação (Mestrado em Educação) Faculdade de Educação da Universidade de Brasília.

TURNER, H. J. Sociologia - Conceitos e Aplicações / Tradução: Marcia Marques Gomes Navas; revisão técnica: João Clemente de Souza Neto - São Paulo: Makron Books, 2000.

VILLELA, W. V.; ARILHA, M. Sexualidade, gênero e direitos sexuais e reprodutivos. In: BERQUÓ, Elza (org). Sexo e Vida: panorama da saúde reprodutiva no Brasil. Campinas, Editora da UNICAMP, 2003. 